\title{
Physical education teachers' wellbeing and its relation with gender
}

\author{
Jorge Both ${ }^{1 *}$, Adriano Ferreti Borgatto ${ }^{2}$, Carlos Augusto Fogliarini Lemos $^{3}$, Vitor \\ Ciampolini $^{2}$, Juarez Vieira do Nascimento ${ }^{2}$
}

ARTIGO ORIGINAL | ORIGINAL ARTICLE

\begin{abstract}
The objective of this study was to evaluate the relation between gender and physical education teachers' wellbeing in southern Brazil, considering the socio-environmental (job satisfaction) and individual (lifestyle) parameters. A total of 1653 teachers (741 men and 912 women) in the states of Paraná, Santa Catarina, and Rio Grande do Sul were surveyed. The instruments used for data collection were QVT-PEF and PEVI, as well as a socio-demographic and professional questionnaire. The results confirm findings concerning dissatisfaction of physical education teachers regarding remuneration, work conditions, job autonomy, work and total life space as well as an overload in women's daily lives. In relation to lifestyle, women showed better eating habits; however, they also showed lower levels of positive behaviour in the components of relationships, and stress control. Therefore, the authors point out to implementation of public policies to ensure more equitable treatment regarding gender issues in the work environment, as well as regarding physical education teachers' personal aspects.

Keywords: Lifestyle, job satisfaction, faculty, teaching.
\end{abstract}

\section{INTRODUCTION}

In recent years several factors have hindered the educational process, and among them teachers' wellbeing has been one of the main affected (Hwang, Bartlett, Greben, \& Hand, 2017; Silveira et al., 2017). This fact also takes place in the physical education (PE) field, especially when considering that several health problems take part during PE teachers' professional career such as lower back pain, voice disorders, common cold, and auditory problems (Kovač, Leskošek, Hadžić, \& Jurak, 2013). Moreover, low salaries, job type, job promotion, bad relationship with colleagues, and poor management have interfered in perceived job satisfaction (Tajnia, Honari, Ranjdust, \& Ebadi, 2014; Yarmohammadi \& Taghibigloo, 2013).

In addition to job-related socio-environmental issues, PE teachers' lifestyle is associated with individual behaviours such as eating habits, physical activity, preventive health actions, relationships, and stress control, all of which have a direct impact on their wellbeing. When socioenvironmental and individual aspects reflect negatively on lifestyle and work environment, physical and/or mental illnesses may arise, affecting the professional's life. Therefore, investigating PE teachers' wellbeing perception and its relation to job satisfaction and lifestyle has been a major topic in this field (Both, Nascimento, Sonoo, Lemos, \& Borgatto, 2014).

In order to understand the factors that contribute to higher job satisfaction perceptions, recent research on PE teachers has examined the differences between genders (Kroupis et al., 2017; Tajnia et al., 2014). In fact, the literature regarding to this topic has no general agreement yet. If on the one hand, gender differences seems not to interfere in job satisfaction (Ahmadian, Farshbaf, \& Vafaeian, 2015; Kroupis et al., 2017); on the other hand, other studies have pointed that women present a higher job satisfaction in comparison to men (Jyothish Kumar \& Manoj, 2015; Tajnia et al., 2014). With regards to PE

Manuscript received at October 23 ${ }^{\text {rd }} 2016$; Accepted at August $18^{\text {th }} 2017$

${ }^{1}$ Londrina State University.

${ }^{2}$ Federal University of Santa Catarina.

${ }^{3}$ Regional Integrated University of the Upper Uruguai and Missions at Santo Angelo.

* Corresponding author: Address: Departamento de Educação Física, Universidade Estadual de Londrina, Rodovia Celso Garcia Cid, PR 445 Km 380, Campus Universitário, P.O. Box 6001, CEP 86051-990, Londrina, Paraná (PR), Brasil. E-mail: jorgeboth@yahoo.com.br 
teachers' lifestyle, women have indicated more stress perception (Kelley \& Gill, 1993) and work overload (Al-Mohannadi \& Capel, 2007); while men are physically more active (Madureira, Maia, \& Fonseca, 2003) and usually present a higher number of injuries than women (Kovač et al., 2013).

In the literature consulted, many factors have influenced PE teachers' work, whether through socio-environmental (job satisfaction) or individual (lifestyle) aspects. However, the results have been presented in a scattered manner and little is known about which factor has the strongest influence on PE teachers' wellbeing. Having a better understanding of those factors can help support national governmental bodies to promote health-related initiatives to enhance the quality of teaching and a better work environment. Therefore, the objective of this study was to evaluate the relation between gender and PE teachers' wellbeing in southern Brazil, considering the socio-environmental and individual parameters.

\section{METHODS}

\section{Study design, participants, and ethics}

This is as descriptive, cross-sectional research (Armour \& Macdonald, 2012). The population consisted of PE teachers actively working at the public state educational system in southern Brazil. In total, the surveyed population consisted of 13.892 teachers, with whom 4.770 teachers were from Parana state, 1.857 were from Santa Catarina state, and 7.265 were from Rio Grande do Sul state.

Sample selection was performed in three phases, consisting of two strata and one stage. The first stratum considered the geopolitical division of the federative units (states) that make up Brazil's south region. The second stratum considered the mesoregions of each state. The single stage considered the Regional Educational Centres (RECs) as conglomerates of the mesoregions of the respective states.

In order to conduct the research, authorizations from the Education Department of each state were obtained, as well as the approval of the Ethics Committee for Human Research at the Federal University of Santa Catarina.

\section{Data collection}

Contacts by phone were made to the RECs to establish partnerships to gather information. When the collaboration for the investigation was accepted, 5.734 survey instruments were sent by mail to the RECs. After receiving the instruments, the RECs forwarded them to the schools. At the schools, the administration of the educational units delivered the questionnaires to the PE teachers, who completed and handed them back to the schools' administration, which returned them to the RECs, and afterwards to the researchers. During all stages the questionnaires were sealed and were opened only by the respondents and researchers. Explanatory letters describing the procedures for data collection were sent to the RECs, school directors and the PE teachers.

In total, 653 teachers from Parana, 580 from Santa Catarina and 411 from Rio Grande do Sul completed the questionnaires, totalling a sample of $1.653 \mathrm{PE}$ teachers. Considering the final sample, the authors calculated a sampling error of 2.27 percentage points through a confidence interval of $95 \%$.

\section{Instruments}

The instruments for data collection consisted of the "Escala de Avaliação da Qualidade de Vida no Trabalho Percebida por Professores de Educação Física do Ensino Fundamental e Médio" (QVT-PEF) ("Rating Scale of Quality of Working Life as Perceived by Physical Education Teachers of the Elementary and Intermediate School") (Both et al., 2006), to evaluate the teachers' job satisfaction; the "Perfil do Estilo de Vida Individual" (PEVI) ("Profile of Individual Lifestyle") (Nahas, Barros, \& Francalacci, 2000), to evaluate the teachers' lifestyle; and a short questionnaire that aimed to characterize the educators' socio-demographic and professional aspects.

The QVT-PEF instrument comprises 34 questions responded through a 7-point Likert scale, which ranges from (1) totally disagree to (7) totally agree. This instrument is based on the theoretical matrix of quality of work life by Walton (1973), who indicates that a job is linked to eight dimensions, namely: remuneration, work 
conditions, job autonomy, opportunities for career advancement, social integration in the workplace, labour laws and regulations, work and the total space of life, and social relevance of the work. Both et al. (2006) conducted an empirical study for the validation of the QVT-PEF, finding acceptable levels of content validity (i.e. 70\%), strong correlations of reproducibility (i.e. $r_{s}$ between 0.82 and 0.69), and high score of reliability (i.e. 0.9482 ).

The PEVI instrument was created by Nahas et al. (2000), which consists of 15 questions distributed in the following components: dietary habits, physical activity, preventive behaviour, relationships, and stress control. The questions are related to the individual's lifestyle characteristics in relation to their wellbeing; there are four frequency options for each healthy behaviour question, in which the score ranges from 0 to 4: (0) "Absolutely not part of my lifestyle", (1) "sometimes corresponds to my behaviour", (2) "almost always true in my behaviour", and (4) "the statement is always true in my daily life and it is a part of my lifestyle". Regarding the validation of the PEVI, Both et al. (2008) conducted a study that revealed acceptable levels of internal consistency (i.e. Conbrach's Alpha $=0.78$ ) and the percentage of explained variance of the questionnaire was $58.65 \%$.

The socio-demographic and professional questionnaire aimed to measure variables to characterize the sample, such as gender, state, life cycles, marital status, professional development cycles, length of time at the institution, academic education, total weekly work hours, and multiple jobs.

\section{Data analysis}

In order to analyse data, we first categorized the components/dimensions and the 'overall assessment of lifestyle and job satisfaction' score using Lemos' (2007) weighting equations. Considering that the sample extrapolated the minimum number of subjects estimated for conducting this study, we also assigned weights to the respondents based on the reverse procedure of probability of selecting the teacher. Afterwards, in order to evaluate the associations between the socio-demographic and professional aspects with gender, the chi-square test was used. To determine the distribution trend of the gender, the chi-square test was employed for a single group, having 50 percent as reference.

To evaluate job satisfaction and lifestyle constructs considering teachers' gender, the likelihood ratio test in the multinomial logistic regression model was employed either in crude or adjusted analyses. It is worth noting that the multinomial logistic regression aimed to perform a detailed analysis of the significant associations found, showing a confidence interval (CI95\%) for odds ratio (OR) of $95 \%$. The adjusted analysis for the multinomial logistic regression added in the model the variables that presented $p \leq 0.10$ in the previous analysis. It should be noted that the independent variables remuneration, work conditions, job autonomy, work and total life space, dietary habits, relationships, and stress control were suppressed from the adjusted analysis models as they were assessed as dependent variables. In the multinomial logistic regression analysis, the category "unsure" in job satisfaction and the category "intermediate profile" in lifestyle were employed to determine the odds ratio of dissatisfied and satisfied teachers regarding job satisfaction and teachers with negative profile and positive profile in lifestyle. The statistical tests were performed through the software SPSS, version 15.0, having $95 \%$ as significance level $(p \leq 0.05)$.

\section{RESULTS}

The results revealed that the majority of the PE teachers were female $(55.2 \%)(p<0.01)$. By analysing the socio-demographic and professional characteristics of the professionals according to the gender of the participants, there was a significant association in the variables corresponding to the state where the teachers work $(p<0.01)$, multi-jobs $(p<0.01)$, marital status $(p<0.01)$, life cycles $(p<0.01)$, and length of work time at the institution $(p=0.03)$ (See Table 1). 
Table 1.

Socio-demographic and professional aspects considering PE teachers' gender

\begin{tabular}{|c|c|c|c|}
\hline Gender & Male $(\%)$ & Female (\%) & $p$ \\
\hline \multicolumn{4}{|l|}{ State } \\
\hline Paraná & 37.8 & 31.6 & \multirow{3}{*}{$<0.01^{a}$} \\
\hline Santa Catarina & 15.4 & 12.8 & \\
\hline Rio Grande do Sul & 46.9 & 55.6 & \\
\hline \multicolumn{4}{|l|}{ Multi-jobs } \\
\hline Do not have & 36.4 & 50.8 & \multirow[t]{2}{*}{$<0.01^{\mathrm{a}}$} \\
\hline Have & 63.6 & 49.2 & \\
\hline \multicolumn{4}{|l|}{ Marital status } \\
\hline Married & 68.6 & 60.1 & \multirow[t]{2}{*}{$<0.01^{\mathrm{a}}$} \\
\hline Others & 31.4 & 39.9 & \\
\hline \multicolumn{4}{|l|}{ Life cycles } \\
\hline Up to 29 years old & 17.4 & 15.2 & \multirow{4}{*}{$<0.01^{\mathrm{a}}$} \\
\hline $30-39$ years old & 30.3 & 37.5 & \\
\hline $40-49$ years old & 35.6 & 39.0 & \\
\hline 50 years or older & 16.7 & 8.4 & \\
\hline \multicolumn{4}{|l|}{ Education } \\
\hline College graduation & 37.8 & 36.7 & \multirow[t]{2}{*}{$0.66^{a}$} \\
\hline Post-graduation & 62.2 & 63.3 & \\
\hline \multicolumn{4}{|l|}{ Professional development cycles } \\
\hline Admission (up to 4 teaching years) & 17.9 & 17.4 & \multirow{4}{*}{$0.08^{\mathrm{a}}$} \\
\hline Consolidation (5 to 9 teaching years) & 20.9 & 29.7 & \\
\hline Diversification (10 to 19 teaching years) & 28.4 & 33.9 & \\
\hline Stabilization (20 or more teaching years) & 32.8 & 28.9 & \\
\hline \multicolumn{4}{|l|}{ Length of work time } \\
\hline Up to 3 years & 30.1 & 31.1 & \multirow{4}{*}{$0.03^{\mathrm{a}}$} \\
\hline 4-11 years & 32.6 & 32.2 & \\
\hline $12-19$ years & 20.3 & 24.4 & \\
\hline 20 years or over & 16.9 & 12.3 & \\
\hline \multicolumn{4}{|l|}{ Total working hours } \\
\hline Up to 40 weekly hours & 44.7 & 48.3 & \multirow[t]{2}{*}{$0.15^{\mathrm{a}}$} \\
\hline 41 weekly hours or over & 55.3 & 51.7 & \\
\hline Total & 44.8 & 55.2 & $<0.01^{\mathrm{b}}$ \\
\hline
\end{tabular}

The results of the other socio-demographic and professional variables showing significant association allowed identifying the teachers' profiles considering the teachers' gender, which were:

- Male: Teachers were from the state of Santa Catarina (15.4\%) and Paraná (37.8\%), they had multiple jobs $(68.6 \%)$, were in a wider age ranges (i.e. up to 29 years old $(17.4 \%)$ and 50 years or older (16.7\%)); and most of them had 20 years or more of work time $(16.9 \%)$.

- Female: Teachers were from the state of do Rio Grande do Sul (55.6\%), they did not have multiple jobs $(50.8 \%)$, were in the intermediate age ranges, (i.e. 30 to 39 years old $(37.5 \%)$ and 40 to 49 years $(39.0 \%)$ ); and most of them had 12 to 19 years of work time $(24.4 \%)$.

About the job satisfaction construct this study found that $65.6 \%$ of the PE teachers in the public state schools in southern Brazil were satisfied with their jobs. Most of the teachers surveyed reported that they were satisfied for the following variables: Social relevance of the work $(79.6 \%)$, labour laws and regulations $(77.8 \%)$, job autonomy $(75.8 \%)$, and opportunities for career advancement $(71.5 \%)$. On the other hand, the dimensions in which the teachers showed the lowest satisfaction rates were: Remuneration (14.5\%), work conditions (39.9\%), work and total life space $(46.2 \%)$, and social integration in the workplace $(53.3 \%)$.

In the evaluation of job satisfaction according to the gender of the participants, significant associations were identified in the dimension of work and total life space for both crude $(\mathrm{p}<0.01)$ and adjusted $(\mathrm{p}=0.03)$ analysis. Work conditions $(p<0.01)$ and job autonomy $(p=0.02)$ showed significant association only in the crude analysis (See Table 2).

In the detailed evaluation of the points that comprise the job satisfaction construct and which presented significant association with gender, this study found that either in the crude or adjusted analysis of the dimension work and total life space, men $[52.3 \%$ (Crude: OR=1.44, CI95\%:1.15-1.81) 
(Adjusted: OR=1.37, CI95\%:1.06-1.79)] showed a higher rate of satisfaction than women $(41.8 \%)$. In the crude analysis of the dimensions work conditions and job autonomy, men $[25.4 \%$ (Crude: $O R=0.75$, CI95\%:0.58-0.96)] had a lower rate of dissatisfaction with work conditions than women $(32.5 \%)$, whereas men reported a higher rate of satisfaction [79.2\% (Crude: OR=1.45, CI95\%:1.12-1.86)] with job autonomy when compared to women (73.4\%) (See Table 2).

Table 2.

Evaluation of job satisfaction considering PE teachers' gender

\begin{tabular}{|c|c|c|c|c|c|}
\hline \multirow{2}{*}{ Gender } & \multicolumn{3}{|c|}{ Job satisfaction } & \multirow{2}{*}{ Crude $p^{\text {a }}$} & \multirow{2}{*}{ Adjusted $p$} \\
\hline & Not satisfied (\%) & Unsure (\%) & Satisfied (\%) & & \\
\hline \multicolumn{6}{|c|}{ Remuneration } \\
\hline Male & 51.0 & 32.8 & 16.3 & \multirow{3}{*}{0.08} & \multirow{3}{*}{0.67} \\
\hline Female & 56.2 & 30.6 & 13.3 & & \\
\hline Total & 54.0 & 31.5 & 14.5 & & \\
\hline \multicolumn{6}{|c|}{ Work conditions } \\
\hline Male & 25.4 & 31.4 & 43.3 & \multirow{3}{*}{$<0.01$} & \multirow{3}{*}{0.14} \\
\hline Female & 32.5 & 30.0 & 37.5 & & \\
\hline Total & 29.6 & 30.6 & 39.9 & & \\
\hline \multicolumn{6}{|c|}{ Job autonomy } \\
\hline Male & 4.1 & 16.7 & 79.2 & \multirow{3}{*}{0.02} & \multirow{3}{*}{0.09} \\
\hline Female & 4.1 & 22.5 & 73.4 & & \\
\hline Total & 4.1 & 20.1 & 75.8 & & \\
\hline \multicolumn{6}{|c|}{ Opportunity for career advancement } \\
\hline Male & 6.2 & 20.2 & 73.6 & \multirow{3}{*}{0.26} & \multirow{3}{*}{0.84} \\
\hline Female & 7.5 & 22.5 & 70.0 & & \\
\hline Total & 7.0 & 21.5 & 71.5 & & \\
\hline \multicolumn{6}{|c|}{ Social integration in the workplace } \\
\hline Male & 9.4 & 35.6 & 55.0 & \multirow{3}{*}{0.29} & \multirow{3}{*}{0.78} \\
\hline Female & 11.5 & 36.5 & 52.0 & & \\
\hline Total & 10.6 & 36.1 & 53.2 & & \\
\hline \multicolumn{6}{|c|}{ Labour laws and regulations } \\
\hline Male & 5.1 & 16.3 & 78.6 & \multirow{3}{*}{0.78} & \multirow{3}{*}{0.41} \\
\hline Female & 5.8 & 17.0 & 77.3 & & \\
\hline Total & 5.5 & 16.7 & 77.8 & & \\
\hline \multicolumn{6}{|c|}{ Work and total life space } \\
\hline Male & 19.4 & 28.3 & 52.3 & \multirow{3}{*}{$<0.01$} & \multirow{3}{*}{0.03} \\
\hline Female & 25.5 & 32.6 & 41.8 & & \\
\hline Total & 23.0 & 30.9 & 46.2 & & \\
\hline \multicolumn{6}{|c|}{ Social relevance of work } \\
\hline Male & 3.1 & 16.3 & 80.6 & \multirow{3}{*}{0.22} & \\
\hline Female & 4.7 & 16.5 & 78.8 & & 0.10 \\
\hline Total & 4.1 & 16.4 & 79.6 & & \\
\hline Overall a & ht of job satisfaction & & & & \\
\hline Male & 7.0 & 24.4 & 68.6 & & \\
\hline Female & 9.1 & 27.5 & 63.4 & 0.07 & 0.06 \\
\hline Total & 8.2 & 26.2 & 65.6 & & \\
\hline
\end{tabular}

a $p$-value estimated by the likelihood ratio test.

${ }^{b} p$-value estimated by the likelihood ratio test adjusted for the following variables: state, multi-jobs, marital status, life cycles, length of time at the institution, professional development cycles, remuneration, work conditions, job autonomy, work and total life space, overall assessment of job satisfaction, dietary habits, relationships and stress control.

With respect to the lifestyle of PE teachers in southern Brazil, the overall assessment of lifestyle showed that $66.9 \%$ of the teachers had positive behaviours. Considering the specific components, the highest rates of positive behaviour were observed in preventive behaviour (80.4\%) and relationships (79.5\%). In contrast, the lowest scores were presented in dietary habits $(38.4 \%)$, stress control $(51.7 \%)$, and physical activity (58.2\%).

In the evaluation of the lifestyle construct considering the gender of the educators, this study found that the components of dietary habits, relationships, and stress control presented a significant association in the crude $(\mathrm{p}<0.01)$ and adjusted $(\mathrm{p}<0.01)$ analysis (See Table 3$)$. 
Table 3.

Evaluation of lifestyle according to gender

\begin{tabular}{|c|c|c|c|c|c|}
\hline \multirow{2}{*}{ Gender } & \multicolumn{3}{|c|}{ Lifestyle } & \multirow{2}{*}{ Crude $p^{\text {a }}$} & \multirow{2}{*}{ Adjusted $p$} \\
\hline & Negative(\%) & Intermediate(\%) & Positive(\%) & & \\
\hline \multicolumn{6}{|c|}{ Dietary habits } \\
\hline Male & 35.5 & 32.6 & 32.0 & \multirow{3}{*}{$<0.01$} & \multirow{3}{*}{$<0.01$} \\
\hline Female & 25.3 & 31.8 & 42.8 & & \\
\hline Total & 29.5 & 32.1 & 38.4 & & \\
\hline \multicolumn{6}{|c|}{ Physical activity } \\
\hline Male & 20.1 & 20.2 & 59.7 & \multirow{3}{*}{0.13} & \multirow{3}{*}{0.06} \\
\hline Female & 18.5 & 24.4 & 57.1 & & \\
\hline Total & 19.2 & 22.7 & 58.2 & & \\
\hline \multicolumn{4}{|c|}{ Preventive behaviour } & \multirow{4}{*}{0.96} & \multirow{4}{*}{0.93} \\
\hline Male & 7.6 & 12.3 & 80.1 & & \\
\hline Female & 7.3 & 12.0 & 80.6 & & \\
\hline Total & 7.4 & 12.2 & 80.4 & & \\
\hline \multicolumn{4}{|c|}{ Relationships } & \multirow{4}{*}{$<0.01$} & \multirow{4}{*}{$<0.01$} \\
\hline Male & 4.3 & 11.1 & 84.6 & & \\
\hline Female & 6.5 & 17.6 & 75.9 & & \\
\hline Total & 5.6 & 14.9 & 79.5 & & \\
\hline \multicolumn{4}{|c|}{ Stress control } & \multirow{4}{*}{$<0.01$} & \multirow{4}{*}{$<0.01$} \\
\hline Male & 18.7 & 22.8 & 58.4 & & \\
\hline Female & 22.8 & 30.3 & 47.0 & & \\
\hline Total & 21.1 & 27.2 & 51.7 & & \\
\hline \multicolumn{4}{|c|}{ Overall assessment of lifestyle } & \multirow{4}{*}{0.42} & \multirow{4}{*}{0.86} \\
\hline Male & 5.6 & 28.7 & 65.7 & & \\
\hline Female & 6.3 & 26.0 & 67.8 & & \\
\hline Total & 6.0 & 27.1 & 66.9 & & \\
\hline
\end{tabular}

Regarding the component dietary habits, this study found that men $[35.5 \%$ (Crude: $\mathrm{OR}=1.37$, CI95\%:1.07-1.76) (Adjusted: $\mathrm{OR}=1.65$, CI95\%:1.25-2.17)] had a higher negative behaviour than women (25.3\%), and men [32.0\% (Crude: OR=0.73, CI95\%:0.58-0.93) (Adjusted: $\mathrm{OR}=0.65$, CI95\%:0.50-0.85)] also had a lower rate of positive behaviour than women $(42.8 \%)$. Concerning relationships, men $[84.6 \%$ (Crude: $\mathrm{OR}=1.77, \quad \mathrm{CI} 95 \%: 1.32-2.37) \quad$ (Adjusted: $\mathrm{OR}=1.68$, CI95\%:1.21-2.33)] had a higher rate of positive behaviour than women $(75.9 \%)$. Similar result was found in the stress control dimension, in which men [58.4\% (Crude: OR $=1.66$, CI95\%:1.31-2.10) (Adjusted: $\mathrm{OR}=1.71$, CI95\%:1.31-2.24)] had a higher positive behaviour rate than women $(47.0 \%$ ) (See Table 3).

\section{DISCUSSION}

Data revealed that the majority of the PE teachers in southern Brazil are women. This fact confirms a trend generally indicated for the teaching profession (Tardif \& Lessard, 2014). Thus, considering that this finding was also reported by other research in different countries (Karimi, Hadavi, Zahedmanesh, \& Ghamarpour, 2015; Yarmohammadi \& Taghibigloo, 2013), it seems that the PE field it is also being influenced by this feminization process. However, one should notice that Parana and Santa Catarina state still indicate a higher number of male PE teachers, which suggests a paradigm still in shift in the southern Brazilian context.

The high incidence of multiple jobs among teachers has been connected with the fact that teachers have other jobs outside the school environment (e.g. team coach, personal trainer, sports manager, etc.) (Silva \& Nunez, 2009). Thus, it appears that the job market for the professionals with bachelor's degree in PE and full teaching degree is conducive to multiple jobs. Another important aspect is that the job offered in public schools means employment and income 
security to the teacher, while the functions performed outside public schools is largely seen as an additional activity to supplement income (Both et al., 2016). For men, the need for extra jobs is probably more evident because they usually are responsible for the largest portion of the household income.

The fact of existing differences between the variables 'life cycles' and 'length of work time' and the teachers' gender may be associated with the legal aspects relating to the national eligibility to retirement. In Brazil, male teachers must work five years more than women to be entitled to retirement (Paraná, 2004; Rio Grande do Sul, 1974; Santa Catarina, 1986). Therefore, considering this characteristic, one can expect the number of men to be greater in the age groups and have longer work time.

Regarding the PE teachers' dissatisfaction, the results indicated higher scores relating to salary and work conditions. However, it was also observed that there was no consistent agreement on the perceived satisfaction relating to the existing ratio between the amount of time devoted to work and leisure, and the social integration that teachers have with the school community. These results were similar to those found in other international studies (AlMohannadi \& Capel, 2007; Koustelios, 2005), which suggest that the issues related to educators are widespread; a clear indication that the public policies in primary education are poor and inadequate. In contrast, the dimensions relating to career advance, autonomy in the educational work, laws that regulate the educational work, and teachers' perception about the relevance of their role in education are aspects that received high satisfaction rates. The results shown in the dimensions affected the results of the overall assessment, where six out of ten teachers reported being satisfied regarding job satisfaction. The influence of the results of dimensions on the overall assessment of job satisfaction can be justified by the similarity of the themes that constitute the work evaluation construct (Both, Nascimento, Sonoo, Lemos, \& Borgatto, 2010).

About the dimensions of the job satisfaction construct, this study showed that work conditions and job autonomy had a significant association only in the crude analysis. That is to say, firstly the higher rate of women's dissatisfaction with work conditions may be associated with the feeling of reduced time to perform work tasks (Ramzaninezha, Hemmatinezhad, Nejadsajadi, \& Keshtan, 2009). On the other hand, women's dissatisfaction with job autonomy may be associated with the fact that men perceived more personal power in the workplace than women (Lindholm, 1997). However, when using the moderating variables in the analyses, the autonomy of the administrative/pedagogical job and the perception of work conditions did not show significant associations with the teachers' gender, indicating similar perceptions on these matters.

Regarding work and total life space, the adjusted analysis confirmed the result of the crude analysis. In fact, men's higher level of satisfaction regarding the ratio between leisure time and work time may be connected with the extra time that women need to spend in family chores when they are out of work, such as child care. Connected with this factor, this study found that men have better relationships interaction, which can also contribute to the relation found in this survey.

With respect to lifestyle, positive ratings were present in these two components: Preventive behaviour and relationships. In contrast, the negative aspects relating to lifestyle were dietary habits, and stress control. The component physical activity had an intermediate result, because only six out of $10 \mathrm{PE}$ teachers reported positive behaviour. This result is of concern because physical educators should put more emphasis on the knowledge and understanding of the importance of physical activity during primary education, which shows that the theory is not consistent with the practice for a significant group of teachers. Furthermore, it should be noted that the result of the frequencies of the lifestyle components had influence on the overall assessment of this construct. A larger number of the teachers studied showed positive behaviours in relation to the overall assessment of lifestyle.

In the analysis of the lifestyle construct considering the gender, three components 
showed significant association. But the number of components that presented relation with gender was not sufficient to affect the overall assessment analysis, which indicates a strong singularity of each component (Both et al., 2008). On the other hand, the associations found in the crude analysis that presented significant relation between the variable gender and the components dietary habits, relationships and stress control were confirmed in the adjusted analysis.

The results showed that women had healthier behaviours with respect to eating habits, and men reported better attitudes regarding relationships and stress. Such results are similar to those found among employees in the Brazilian industry (National Industry Confederation, 2009). In addition, women's dietary habits may be associated with a higher level of concern with body image, which is connected with a cultural aspect, for example, that women tend to have a more critical view of their own body (Veggi, Lopes, Faerstein, \& Sichieri, 2004). On the other hand, the findings on the component relationships may be connected with the fact that men have more group leisure activities (Del Duca, Oliveira, Sousa, Silva, \& Nahas, 2011).

The information provided on stress control may be connected with the fact that men are less prone to burnout as a result of work problems when compared to women (Brudnik, 2010). Furthermore, it should be emphasized that the pre-menstrual syndrome, a highly prevalent disorder among women in fertility age, may alter negatively women's mood for a significant period of time every month (Vieira \& Gaion, 2009).

\section{Limitations of the Study}

Some limitations of this study should be mentioned. The self-administered application method allows a risk of inaccuracy of data considering the less interaction between researcher and subject. Added to this risk is the non-observation of the respondents' behaviour by the researcher, which is limited to the information contained in the instruments. In addition, although the sampling error presented an excellent score, this calculation was performed with the assumption that the sample was chosen randomly, which was not the case in this study considering that people self-selected to participate.

Another limitation is that even though this research presents a good representation of teachers in each state and REC, which allowed an acceptable sampling error for this study, the authors did not control the number of subjects with each socio-demographic characteristic investigated, which would ensure the analysis of heterogeneous individuals presenting different profiles.

\section{CONCLUSION}

The findings of this study allow us to conclude that most of the PE teachers in southern Brazil are satisfied with their job and present positive lifestyle behaviours. However, the most negative aspects regarding to their job satisfaction and lifestyle are remuneration and dietary habits, respectively. When considering gender comparisons, men reported being more satisfied with work and total life space with regards to job satisfaction, as well as showing better relationship and stress control behaviours. On the other hand, women presented significantly better dietary habits. Finally, as a suggestion, there is a need for the implementation of public policies to ensure more equitable treatment regarding gender issues in the work environment, as well as regarding PE teachers' personal aspects.

Acknowledgments:

CNPq.

Conflict of interests:

Nothing to declare.

Funding:

CNPq.

\section{REFERENCES}

Ahmadian, R., Farshbaf, M., \& Vafaeian, M. (2015). The relationship between burnout and job satisfaction of physical education techers in Shabestar City. Indian Journal of Fundamental and Applied Life Sciences, 5(S2), 1235-1241.

Al-Mohannadi, A., \& Capel, S. (2007). Stress in physical education teachers in Qatar. Social 
Psychology of Education, 10(1), 55-75. http://doi.org/10.1007/s11218-006-9004-9

Armour, K., \& Macdonald, D. (Eds.). (2012). Research methods in physical education and youth sport. Abigdon, OX: Routledge.

Both, J., Borgatto, A. F., Nascimento, J. V., Sonoo, C. N., Lemos, C. A. F., \& Nahas, M. V. (2008). Validation of the "Individual Lifestyle Profile" scale. Revista Brasileira de Atividade Física e Saúde, 13(1), 5-14.

Both, J., Borgatto, A. F., Sonoo, C. N., Lemos, C. A. F., Ciampolini, V., \& Nascimento, J. V. (2016). Multiple Jobholding associated with the wellbeing of physical education teachers in southern Brazil. Educación Física y Deporte, 35(1). http://doi.org/10.17533/udea.efyd.v35n1a05

Both, J., Nascimento, J., Sonoo, C., Lemos, C., \& Borgatto, A. (2010). Worker's life conditions in the teaching profession: Association between lifestyle and quality of life at work among physical education teachers. Motricidade, 6(3), 39-51.

Both, J., Nascimento, J. V., Lemos, C. A. F., Donegá, A. L., Ramos, M. H. K. P., Petroski, E. C., \& Duarte, M. D. F. D. S. (2006). Quality of life at work by physical education teachers. Revista Brasileira de Cineantropometria e Desempenho Humano, 8(2), 4552.

Both, J., Nascimento, J. V., Sonoo, C. N., Lemos, C. A. F., \& Borgatto, A. F. (2014). Wellness of physical education teacher of southern region of Brazil according to the life cycles. Revista Brasileira de Educação Física e Esporte, 28(1), 77-93. http://dx.doi.org/10.1590/S180755092014000100077

Brudnik, M. A. R. I. A. (2010). Macro-paths of burnout in physical education teachers and teachers of other general subjects. Studies in Physical Culture and Tourism, 17(4), 353-365.

Del Duca, G. F., Oliveira, E. S. A. d., Sousa, T. F. d., Silva, K. S. d., \& Nahas, M. V. (2011). Physical inactivity during leisure-time among industrial workers from the State of Rio Grande do Sul, Brazil. Motriz, 17(1), 180-188. http://dx.doi.org/10.5016/19806574.2011v17n1p180

Hwang, Y.-S., Bartlett, B., Greben, M., \& Hand, K. (2017). A systematic review of mindfulness interventions for in-service teachers: A tool to enhance teacher wellbeing and performance. Teaching and Teacher Education, 64, 26-42. http://doi.org/10.1016/j.tate.2017.01.015

Jyothish Kumar, L. K., \& Manoj, T. I. (2015). Job satisfaction among physical education teachers of secondary school in Kerala, India. International Journal of Engineering Research and Sports Science, 2(11), 1-5.

Karimi, M., Hadavi, S. F., Zahedmanesh, F., \& Ghamarpour, S. (2015). The relationship between organizational climate, job stress, job burnout of the physical education teachers: A case of the schools at Islamshahr, Iran. Research Journal of Recent Sciences, 4(5), 114-119.
Kelley, B. C., \& Gill, D. L. (1993). An examination of personal/situational variables, stress appraisal, and burnout in collegiate teacher-coaches. Research Quaterly for Exercise and Sport, 64 (1), 94102.

http://dx.doi.org/10.1080/02701367.1993.1060 8783

Koustelios, A. (2005). Physical education teachers in Greece: Are they satisfied? International Journal of Physical Education, 42(2), 85-90.

Kovač, M., Leskošek, B., Hadžić, V., \& Jurak, G. (2013). Occupational health problems among Slovenian physical education teachers. Kinesiology, 45(1), 92-100.

Kroupis, I., Kourtessis, T., Kouli, O., Tzetzis, G., Derri, V., \& Mavrommatis, G. (2017). Job satisfaction and burnout among Greek PE teachers. A comparison of educational sectors, level and gender. Cultura, Ciencia y Deporte, 12(34), 5-14. http://dx.doi.org/10.12800/ccd.v12i34.827

Lemos, C. A. F. (2007). Quality of life in the professional career of public schools physical education teachers in the state of Rio Grande do Sul. (master's dissertation in physical education), Federal University of Santa Catarina, Florianópolis, Brazil.

Lindholm, J. A. (1997). Secondary school physical education teacher motivation: An application of personal investment theory. Journal of teaching in physical education, 16(4), 426-439. http://dx.doi.org/10.1123/jtpe.16.4.426

Madureira, A. S., Maia, M. F. M., \& Fonseca, S. A. (2003). Lifestyle and physical activity of the physical education professor. Revista Brasileira de Cineantropometria e Desempenho Humano, 5(1), 5462.

Nahas, M. V., Barros, M. V., \& Francalacci, V. (2000). Conceptual basis for a simplified wellness assessment instrument. Revista Brasileira de Atividade Física \& Saúde, 5(2), 48-59. http://dx.doi.org/10.12820/RBAFS.V.5N2P4859

National Industry Confederation. (2009). Quality of life across physical education teachers' carrer in state public teaching - RS - Brazil: General report. In M. V. Nahas (Ed.), (pp. 163). Retrieved from http://www.sesimt.com.br/arquivos/415_book_1 azer_ativo_internet.pdf.

Paraná (2004). Public State Law, no. 103/2004. Establishes and ordain about teachers' career path of the Paraná state system of basic education and adopts other measures.

Ramzaninezha, R., Hemmatinezhad, M. A., Nejadsajadi, A., \& Keshtan, M. H. (2009). Job retention factors among physical educators. World Journal of Sport Science, 2(3), 154-159.

Rio Grande do Sul (1974). Public State Law, no. 6.672. Statute and career path of the public school teachers of Rio Grande do Sul.

Santa Catarina (1986). Public State Law, no. $6.844 / 1986$. Ordain about the statute of state public school teachers in the state of Santa Catarina. 
Silva, J. V. P., \& Nunez, P. R. M. (2009). Quality of life, demographic profile and professional of physical education teachers. Pensar a Prática, 12(2), 1-11. http://dx.doi.org/10.5216/rpp.v12i2.3795

Silveira, R. C. d. P., Ribeiro, I. K. d. S., Teixeira, L. N., Teixeira, G. S., Melo, J. M. A., \& Dias, S. F. (2017). Wellness and health of teachers in a public educational institution. Journal of Nursing UFPE on line, 11(3), 1481-1488. doi: 10.5205/reuol.10263-91568-1RV.1103sup201721

Tajnia, J., Honari, H., Ranjdust, S., \& Ebadi, N. (2014). Job Satisfaction of Physical Education Teachers in East Azerbaijan Province, Iran. Bulletin of Environment, Pharmacology and Life Sciences, 3(Suppl. 2), 57-62.

Tardif, M., \& Lessard, C. (2014). Teaching work: Elements for a theory of teaching as a profession of human interactions. ( $9^{\text {th }}$ ed.) Petrópolis, RJ: Vozes.
Veggi, A. B., Lopes, C. S., Faerstein, E., \& Sichieri, R. (2004). Body mass index, body weight perception and common mental disorders among university employees in Rio de Janeiro. Revista Brasileira de Psiquiatria, 26(4), 242-247. http://dx.doi.org/10.1590/S151644462004000400007

Vieira, L. F., \& Gaion, P. A. (2009). Impact of premenstrual syndrome in the mood state of athletes. Jornal Brasileiro de Psiquiatria, 58(2), 101106. http://dx.doi.org/10.1590/S004720852009000200006

Walton, R. E. (1973). Quality of working life: What is it? Sloan management review, 15(1), 11-21.

Yarmohammadi, S., \& Taghibigloo, N. (2013). An Investigating into Factors Influencing Job Satisfaction of Physical Education Teachers in Zanjan Province. International Journal of Basic Sciences \& Applied Research, 2(1), 13-16.

All content of Journal Motricidade is licensed under Creative Commons, except when otherwise specified and in content retrieved from other bibliographic sources. 